\title{
Research on the Behavioral Game of Tax Collection and Management Subject Under the Tax Agency Mode
}

\author{
Min-jiao PENG, Zhu FANG* and Min WANG
}

\author{
School of Economics, School of Finance and Public Administration \\ Yunnan University of Finance and Economics \\ Yunnan, Kunming, China
}

${ }^{*}$ Corresponding author

\section{Keywords: Taxpayer; Tax Agency; Tax Supervision Department; Game Theory.}

\begin{abstract}
Taxation is the main source of China's fiscal revenue. The main body of tax collection and management is the executor of the entire tax collection and management activities. It is of great significance to study the behavior patterns between tax collection and management entities. This paper analyzing the behavior mode of tax administration subject by constructing the game model of taxpayer with tax agency and the game model of tax agency with taxation supervision department, the main factors affecting the behavior of tax collection and management are obtained from the deduction of the game model, which provides a policy basis for better tax collection and management.
\end{abstract}

\section{Introduction}

Taxation is the main source of fiscal revenue in China. According to the statistics of China Economic Net, more than $85 \%$ of fiscal revenue comes from tax revenue. Tax collection and management includes three links of levy, management, and investigation, and four main actors of government departments, tax authorities, taxpayers, and tax agencies. The levy, that is, the tax collection, the main body of the behavior includes the relevant tax authorities and taxpayers. For the tax authorities, its main duties are to enforce the tax law, act in accordance with the law, and levy according to the rate. For taxpayers, their main obligations are to comply with tax laws, pay taxes according to rates, and consciously pay taxes; management, that is, tax management, the main actors are mainly government departments. The main tasks include establishing and improving various tax collection and management systems, and rationally managing taxes. Better for the government to achieve macro-control, rational allocation of resources and income distribution of functional services; check, that is, tax audit, its main body of conduct is the relevant tax regulatory department, the main function is to verify the tax authorities and taxpayers have violated tax policies and relevant laws and regulations, supervision of tax authorities to levy taxes according to law, taxpayers pay taxes according to law. In addition, with the development of China's economy, the change of economic structure and the complicated management methods, a fourth type of behavioral entity, namely the tax agency, has been created in the tax collection and management. Its main function is to charge taxpayers for various taxation matters. In the three links of tax collection and management, the four actors are not only different from each other but also related to each other, which together constitute the organic whole of tax collection and management activities, and affect the smooth progress of tax collection and management activities.

\section{Literature Review}

The structure of the tax system and its nature restrict government behavior (Wang Wei, 2014). The annual tax loss caused by the corruption of tax collectors in China reaches $7.6 \%-9.1 \%$ of GDP [2]. Xian Chunlong (2012) believed the tax authorities would use the power to reduce the rate of seizures, the rate of punishment, or deliberately cover up undeclared income, resulting in the loss of state tax revenue [3]. Compared with the government and tax authorities, taxpayer behavior is more complicated and diverse [4]. The factors affecting taxation behavior include not only their own 
factors, but also the influence of the government and other environment [5].

The first to introduce taxpayer behavior into the model was Michael G. Allingham and Agnar Sandmo [6]. Later scholars of the study expanded on this model. John H. Pencavel (1979) and others will be moral, democratic, etc [7]. Economic factors take into account the impact of taxpayer behavior. Pommerehne, Albert Hart and Frey (1994) conducted a dynamic regression analysis of the relationship between government public product provision, government waste, fairness and taxpayer compliance [8]. Alm et al. (1992) pointed out that expectations theory could be used to explain people's tax behavior [9]. McCaffery, Slemrod (2006) and Chu Deyin, Han Yiduo (2016) introduced behavioral economics on the basis of predecessors $[10,11]$.

China's research on tax agency began in the late 1980s and has become a relatively independent intermediary structure in China [12], but there are still many problems [13], regulating tax agency behavior has become the key to its healthy development [14].

By reading domestic literature on the study of tax subject behavior patterns, it is found that the research on tax collection and management subjects in China mainly focuses on taxpayers, while there are few studies on tax authorities, tax agencies and taxation authorities. Based on this, this paper will introduce game theory to study the behaviors among the main subjects, in order to provide reference for the smooth development of tax collection and management.

\section{Theoretical Analysis and Research Hypothesis}

Game theory is the study of the decision-making process when the behavior of the decision-making body interacts directly and the equilibrium problem of such decision-making [15]. To become an applicable field of game theory, it is necessary to have the following factors: first, there must be participants with conflicts of interest; second, participants always take corresponding actions according to the strategies that the opponent may adopt; third, the participants are always pursue maximum self-interest [16]. In the game of taxation and management related behaviors studied in this paper, there are just three factors. First, the tax authorities, taxpayers, tax agencies and taxation authorities are participants with conflicts of interest. Second, the tax authorities, taxpayers, tax agencies, and tax authorities will choose the most favorable strategy according to relevant laws and regulations, macroeconomic operating conditions, and the level of supervision of law enforcement agencies. These strategies have clear boundaries. Each of them has at least two action strategies, each of which has an impact on the interests of other actors. Therefore, it is feasible to use game theory to study the behavior patterns between tax collection and management subjects.

\section{Model Establishment}

The game is derived from the conflicts and cooperation between the various game subjects because of the interests. To establish a game model between the game subjects, we must first understand the behavior between these subjects. Therefore, before establishing the game model, this chapter will first analyze the behavior of each tax collection subject.

\subsection{Analysis of the behavior of all parties in the game}

\subsubsection{Tax agency behavior analysis}

As a rational economic person, the tax agency provides services for taxpayers according to their professional knowledge and service attitude. It can be divided into high-quality agency service and inferior agency service. The effect of the service provided by the tax agency and the taxpayer's personal handling of tax-related affairs In comparison, there are three cases of greater than, less than, and equal to. In this paper, the first case is defined as a good agent, and the second and third cases are defined as inferior agents. If the tax agency provides a quality agent to the taxpayer, then regardless of whether the taxation authority checks it, the tax agency's benefits are fixed, that is, the taxpayer pays the agency fee; however, if the tax agency provides a poor quality agent to the taxpayer, there will be two situations. One is that the supervisory department finds out its inferior 
agent behavior. At this time, the tax agency will reduce its income because of the fine; the other is not the supervision department. In this case, the tax agency can obtain more profits than it provides quality services. Therefore, what type of service the tax agency provides is related to the intensity of the fines provided by the tax authorities for providing inferior services and the probability of inspection.

\subsubsection{Taxpayer behavior analysis}

The taxpayer referred to in this article, that is, the principal of tax agent behavior, is the general term for taxpayers and withholding agents. In the game model of the principal-agent relationship formed between the taxpayer and the tax agent, there are two types of taxpayer's action strategies: the principal agency and the non-authorized agency. When a taxpayer entrusts a tax intermediary, if the commissioned agency is a tax agency that provides quality services, the taxpayer's utility from its high-quality agency service is greater than the effectiveness of the tax-related matters. However, if the entrusted tax agency provides inferior agency services, the taxpayer will suffer losses from its non-professional agency services, thereby making the taxpayer's utility less than the effectiveness of personally handling the tax-related affairs; when a taxpayer does not entrust a tax agency, the taxpayer has a fixed payment, and its utility is fixed, and this utility is a comparison value of the principal agency. In the complete information static game, it is assumed that the taxpayer is a rational economic person.

\subsubsection{Regulatory behavior analysis}

In China, the institutions responsible for tax supervision mainly include the China Association of Certified Tax Agents and the relevant tax administration agencies, and their respective duties are not the same, but in this paper, in order to facilitate the modeling, they are collectively referred to as the tax supervision department; the regulatory action strategy is also divided into two types, namely, tax inspection and non-examination. When the taxation supervision department inspects the tax agency, on the one hand, the taxation supervision department will pay a fixed supervision cost. On the other hand, as long as the taxation supervision department inspects the tax agency to provide the taxpayer with inferior service, the tax agency will impose a certain amount of fines; if the taxation supervision department does not check the taxation agency, the taxation supervision department will not pay the expenses incurred due to supervision, but if the superior department of the supervision department checks the relevant tax agency to provide the inferior service, not only will the tax agency be fined (assuming the amount of fines is the same as that of the tax authorities), and the tax authorities will be subject to disciplinary action. At this time, for the taxation supervision department, the consideration of maximizing its benefits includes not only the supervision cost, the fine income, its own salary and other factors, but also the pressure given by the superior.

Based on the above analysis, the taxpayers, tax agencies and taxation authorities are regarded as a decision-making body respectively, and two game models are established, that is, the game model of taxpayers and tax agencies and the game model of tax agents and regulatory authorities.

\subsection{Game model of taxpayers and tax agencies}

The relationship between taxpayers and tax agencies is an obvious principal-agent relationship. Using the asymmetry of information in the principal-agent mechanism, this paper constructs a pure strategy game payment matrix to study and analyze the selection strategies of taxpayers and principal agencies (as shown in Table 1).

Table 1. Payment matrix of taxpayer and tax agent game model

\begin{tabular}{l|c|c}
\hline & Quality agent $(\beta)$ & Inferior agent $(1-\beta)$ \\
\hline Commission () & $\left(U_{1}, T_{1}\right)$ & $\left(U_{2}, T_{2}\right)$ \\
\hline Not commissioned $(1-)$ & $(U, 0)$ & $(U, 0)$ \\
\hline
\end{tabular}

In Table 1, $U$ indicates the utility of the taxpayer in personally handling the tax-related affairs, where $U$ is determined by income $(\mathrm{Y})$, tax rate $(\mathrm{t})$ and the cost of handling tax-related matters $(\mathrm{C})$, that is, $\mathrm{U}=\mathrm{U}(\mathrm{Y}, \mathrm{t}, \mathrm{C}) ; U_{1}$ indicates the taxpayer's utility when the taxpayer chooses a quality tax 
agency to represent his tax-related business. $U_{1}$ is determined by the taxpayer's income (Y), tax rate ( $\mathrm{t}$ ), and payment to the tax agent $(\mathrm{M})$, that is $U_{1}=U_{1}(\mathrm{Y}, \mathrm{t}, \mathrm{M}) ; U_{2}$ indicates the utility of the taxpayer's choice of a poor tax agency to handle tax-related matters, and its utility with the quality utility function. Similarly, just because the tax agency provides inferior agency services, it is equivalent to the taxpayer paying more $\mathrm{M} ; T_{1}$ refers to the utility of the tax agency when providing quality services, and this utility is determined by the remuneration $(\mathrm{M})$ paid by the taxpayer and the cost $(\mathrm{K})$ of the tax-related transaction, that is, $T_{1}=T_{1}(\mathrm{M}, \mathrm{K}) ; T_{2}$ represents the utility of the tax agency to provide taxpayers with inferior services, and $T_{1}, \mathrm{~T}, T_{2}$ is equivalent to paying less the tax expense $\mathrm{K}$, it is possible to reap excessive profits. In the above utility, we assume that $\mathrm{U}, U_{1}, U_{2}$, $T_{1}, T_{2}$ are all greater than zero, and $U_{1}>U>U_{2}, T_{1}<T_{2}$.

According to the scribing method in game theory, the Nash equilibrium is obtained, and the Nash equilibrium is "not commissioned, inferior agent", that is, if the taxpayer chooses not to entrust, the tax authority chooses to provide inferior service and to provide inferior quality for the tax agent. The proxy service is a dominant strategy for it. It can be seen that if the tax agency has been providing inferior agency services under the market mechanism, the taxpayer will suffer losses and choose not to act as an agent, and the tax agency will also disappear from the industry. Obviously, from the perspective of maximizing the overall interests of society, this conclusion is contrary to reality.

When the government intervenes in the tax agency, it assumes that the proportion of all high-quality agencies in the market is $\delta$, and the proportion of inferior agency services is $1-\delta$. Because of the asymmetric information in the market, the tax agency knows whether it is capable. Providing quality agents, taxpayers are unable to distinguish the advantages and disadvantages of the agency services provided by tax agencies when conducting agency. Therefore, the utility of taxpayers entrusted and not commissioned by tax agencies depends on the proportion of high-quality tax agencies in the market. The expected utility is:

$$
U E_{1}=\delta U_{1}+(1-\delta) T_{2} ; U E_{2}=U
$$

Under the premise of pursuing the maximization of the overall benefits of society, the government must ensure the continued existence of tax agencies, then it must meet:

$$
U E_{1} \geq U E_{2} ; \delta U_{1}+(1-\delta) T_{2} \geq U(0<\delta<1)
$$

Thereby getting: $\quad \delta^{\prime} \geq\left(U-T_{2}\right) / U_{1}-T_{2}$. In other words, only when the proportion of tax agencies providing quality services accounts for $\delta^{\prime}$ and above, taxpayers will choose to entrust tax agencies to handle tax-related matters, and the tax agency industry can continue to maintain.

Through the game model between taxpayers and tax agencies, it can be concluded that in the early stage of the establishment of the tax agency market, the government's supervision and guidance is crucial. Only under the supervision of government departments, it provides high-quality tax agency services. The tax agency accounts for a certain share of the market and creates effective tax agency requirements for it to ensure the legitimate rights and interests of taxpayers and the survival and healthy development of tax agencies.

\subsection{Game model of tax agency and supervision}

Table 2. Revenue matrix between tax agency and tax regulatory agency

\begin{tabular}{l|c|c}
\hline & Quality agent $(\delta)$ & Inferior agent $(1-\delta)$ \\
\hline Check $(\alpha)$ & $\left(\mathrm{S}, P_{1}\right)$ & $\left(\mathrm{F}+\mathrm{S}, P_{2}\right)$ \\
\hline Not check $(1-\alpha)$ & $\left(0, P_{1}\right)$ & $\left(\mathrm{H}, P_{2}\right)$ \\
\hline
\end{tabular}

Based on the game model above, this paper further deepens and establishes a hybrid game model between the tax agency and the taxation supervision department. The taxation supervision department will consider the inspection probability and punishment of the tax agency into the model. As with the model above, the revenue matrix between the tax agency and the tax regulatory 
structure is first constructed (Table 2).

In order to facilitate the construction of the equation below, the letters in Table 2 are distinguished from the letters obtained in Table 1 for the utility obtained by each game subject, and represent the gains obtained by each game subject. That is, $\mathrm{S}$ represents the income of the tax supervision department when conducting inspections, and this income is negative, which represents the inspection cost; $P_{1}$ represents the income of the tax agency when providing quality service, $P_{1}=\mathrm{M}-\mathrm{K} ; P_{2}$ indicates that the tax agency provides poor service when it gets the benefits. When the tax collection and management department conducts inspection, $P_{2}=M-K^{\prime}-F$; when the tax collection and management department does not conduct inspection, $P_{2}^{\prime}=M-K^{\prime}$, where $K$ indicates that the tax agency provides the inferior agency service. The cost of tax payment $\left(K^{\prime}<K\right)$, $\mathrm{F}$ indicates the fine for the inferior tax agency investigated and dealt with; $\mathrm{H}$ indicates the income when the tax supervision department is arbitrarily departed from the job and the superior department checks the inferior tax agency. This income is also negative. In addition, indicates the probability of inspection by the taxation authority, $\delta$ is the same as above, indicating the coverage of quality tax agencies.

From the perspective of pure strategy Nash equilibrium, there is no Nash equilibrium in the model, but according to the Nash theorem, the game between the tax agency and the taxation authority contains at least a mixed strategy Nash equilibrium. In this paper, the optimal reflection function is used to solve the mixed Nash equilibrium in the model.

\subsubsection{Analysis of the optimal response function of the regulatory authorities}

Using $E_{1}$ to represent the expected benefits that the tax regulatory authorities receive in the game, the optimal response function of the regulator is:

$$
E_{1}=\alpha[\delta S+(F+S)(1-\delta)]+(1-\alpha)(1-\delta) H
$$

Solve the first derivative of and make it equal to zero:

$$
\delta^{\prime}=1+S /(F-H),(H<0)
$$

That is to say, when $\delta=\delta$, the taxation supervision department obtains the maximum benefit; when $\delta<\delta^{\prime}$, it means that the proportion of high-quality tax agencies in the market is too small, and the taxation supervision department is inevitably maximizing its utility. It will strengthen the supervision of tax agencies and increase the proportion of high-quality tax agencies; when $\delta>\delta^{\prime}$, there are more high-quality tax agencies in the market, and the regulators will reduce the tax for maximizing utility. The supervision of the agency saves the cost of supervision. With the laxity of the taxation supervision department, the inferior tax agency will increase. Therefore, in the end, the quality tax agency in the market will reach equilibrium in the dynamic, and this equilibrium tends to $\delta^{\prime}$.

\subsubsection{Optimal response function and analysis of tax agencies}

Using $E_{2}$ to represent the expected benefits of the tax agency in the game, the expected benefits from the tax agency are:

$$
E_{2}=\left(2 M-K-K^{\prime}-1+F \alpha\right) \delta+M-K^{\prime}-F \alpha+1
$$

Find the first derivative of $\delta$ and make it equal to zero, and get: $2 M-K-K-1+F \alpha$, so that:

$$
\alpha^{\prime}=\left(K+K^{\prime}+1-M\right) / F
$$

That is, when $\alpha=\alpha^{\prime}$, the tax agency receives the most revenue. When $\alpha<\alpha^{\prime}$, the taxation supervision department has a low probability of inspection, and the tax agency is less likely to be inspected to provide a poor tax agent. At this time, the tax agency industry can obtain a poor tax agency service. Excessive profits, attracted by excess profits, the proportion of inferior tax agencies will increase, so that the tax supervision department will strengthen supervision, increase; when $\alpha>\alpha^{\prime}$, the tax supervision department will increase the probability of inspection by tax agencies. Large, tax agencies are less likely to provide inferior tax agency services. At this time, regulators will reduce inspections in order to save costs, so will decrease. Therefore, the supervision of the 
taxation supervision department also tends to be balanced in the dynamics, and this equilibrium is $\alpha=\alpha^{\prime}$.

\subsubsection{Equilibrium state analysis}

The analysis of the optimal response function of the taxation supervision department and the tax agency shows that when the $\delta=\delta^{\prime}$ tax agency pursues the maximization of interests to achieve equilibrium, when $\alpha=\alpha^{\prime}$, the taxation supervision department also reaches equilibrium, therefore, When and $\alpha=\alpha^{\prime}$ are satisfied, the taxation supervision department and the taxation agency realize the equilibrium in the mutual game of maximizing the interests of each other, that is, establishing the Nash equilibrium under the hybrid strategy solved by the model. In this equilibrium state, the two sides of the game each achieve Pareto optimality, that is, each party will not change its own action strategy.

\section{Conclusion and Enlightenment}

Based on the game model of taxpayer and tax agent established in the article and the game model of tax agency and taxation supervision department, the following conclusions can be drawn: first, the emergence of tax agencies has improved the overall benefits of society, not only saving the direct costs and additional burdens of taxpayers, but also making tax returns accurate and efficient in a timely manner. However, in an unregulated market, due to the asymmetry of information, the tax agency will pursue the maximization of benefits and will choose to provide inferior agency services to the entrusted taxpayers. Second, when the tax agency performs agency activities, the key to providing high-quality or inferior agency services is the cost of handling tax-related matters. The penalty and the trade-offs of the agent fees given by the taxpayer. Third, for the tax regulatory authorities, there is also a trade-off between supervision costs, superior pressures and benefits.

Based on the above deductive analysis of the behavior of tax collection and management, this paper proposes the following policy recommendations: taxpayers should raise awareness of discrimination, prevent moral hazard, and entrust quality tax agencies; tax agencies should constantly improve their services and improve their taxation capacity. Reduce the cost of taxation and provide high-quality tax agency services; relevant government departments and taxation supervision departments should continuously improve China by reducing supervision costs, improving disciplinary deterrence, improving internal supervision and social supervision, and establishing incentive compatibility mechanisms. The proportion of quality agents in the tax agency market is to promote the healthy development of China's tax agency industry and make it better for taxpayers.

\section{Acknowledgement}

This research is financially supported by the Research on Tax Collection and Management Mode under the Background of "Internet+" (17ZDA053); Research on Tax Gap Measurement System and Tax Policy Analysis Expansion Model (71163044).

\section{References}

[1] Wang Tong. The Reform of Tax System and the Transformation of Government Behavior Model [J]. Theory Exploration, 2014 (5): 95-99. (In Chinese)

[2] Hu Angang. China: Challenge Corruption [M]. Hangzhou: Zhejiang People's Publishing House, 2001: 61. (In Chinese)

[3] Xian Chunlong. Research on the Loss of Personal Income Tax in China and Its Causes [M]. Beijing: China Economic Publishing House, 2012. (In Chinese)

[4] Tian Lihua, Yang Fusheng. An Empirical Study of Taxpayer Behavior-Based on the 
Investigation of the Status of Individual Income Tax Payment of Natural Taxpayers in Jiangsu Province [J]. Reports Research, 2008 (3): 74-77. (In Chinese)

[5] Li Junsheng, Lin Xiuxiang. Analysis of Factors Affecting Taxation Behavior of Chinese Enterprises-Taxation Questionnaire from Enterprises and Governments and Its Enlightenment [J]. Financial Research, 2007 (01): 73-77. (In Chinese)

[6] Allingham, Michael G. and Sandmo, Agnar. Income Tax Evasion: A Theoretical Analysis [J]. Journal of Public Economics, 1972, 1 (3-4): 323-338.

[7] Pencavel, John H. A Note on Income Tax Evasion, Labor Supply, and Nonlinear Tax Schedules [J]. Journal of Public Economics, 1979, 12 (1): 115-124.

[8] Pommerehne, Werner W., Hart, Albert and Frey, Bruno S. Tax Morale, Tax Evasion and the Choice of Policy Instruments in Different Political Systems [J]. Public Finance, 1994, 49 (Supplement): 52-69.

[9] Alm J., Mcclelland G. H., Schulze W. D. Why Do People Pay Taxes? [J]. Journal of Public Economics, 2004, 48 (1): 21-38.

[10] McCaffery Edward J. and Slemrod Joel. Behavioral Public Finance [M]. Russell Sage Foundation. 2006: 1-26.

[11] Chu Deyin, Han Yiduo. Analysis of Tax Compliance Based on the Perspective of Behavioral Economics [J]. Tourty Research, 2016 (5): 109-112. (In Chinese)

[12] Yu Jianchun. Analysis on the Perfection of Tax Interrogation System of Tax Intermediary Organizations [J]. Modern Economic Information, 2014 (10): 121-121. (In Chinese)

[13] Chen Liwen. Problems and Countermeasures in China's Tax Agency [J]. Reformation and Strategy, 2007 (5): 65-67. (In Chinese)

[14] Zhao Huaitan. Standardizing Tax Agency Behavior Establishing a Good Social Image [J]. China Taxation, 1998 (7): 16-18. (In Chinese)

[15] Zhang Weiying. Game Theory and Information Economics. New 1st Edition [M]. Gezhi Publishing House, 2012. (In Chinese)

[16] Qin Kai, Wang Yongqun, Wang Wei, et al. The Perfection of Tax Integrity System from the Perspective of Game Theory [J]. Tax Research, 2017 (12). (In Chinese) 